Rev. Interd. em Cult. e Soc. (RICS), São Luís, v. 7, n. 1, p. 242 - 258, jan./jun. 2021

ISSN eletrônico: 2447-6498

\title{
Acessibilidade nos museus de arte a partir da parametrização de obras: Fundação Iberê Camargo ${ }^{1}$
}

\section{Accessibility in art museums based on the parameterization of works: Fundação Iberê Camargo}

\author{
CRISTIANO DA CUNHA PEREIRA \\ Mestre em Indústria Criativa pela FEEVALE; \\ Doutorando em Design e Tecnologia pela \\ Universidade Federal do Rio Grande do Sul (UFRGS). \\ cristianocunhadesign@hotmail.com \\ CRISTIAN FAGUNDES \\ Mestre em Design e Tecnologia pela \\ Universidade Federal do Rio Grande do Sul (UFRGS); \\ Doutorando em Design e Tecnologia pela \\ Universidade Federal do Rio Grande do Sul (UFRGS). \\ fagundes.cristian@gmail.com \\ TÂNIA LUISA KOLTERMANN DA SILVA \\ Doutora em Engenharia de Produção pela \\ Universidade Federal de Santa Catarina (UFSC); \\ Professora no Programa de Pós-Graduação em Design (UFRGS). \\ tania.koltermann@ufrgs.br \\ UNDERLÉA MIOTTO BRUSCATO \\ Doutora em Arquitetura pela \\ Universidade Politécnica da Catalunha (UPC); \\ Professora no Programa de Pós-Graduação em Design (UFRGS). \\ arq.leiab@gmail.com
}

\section{RESUMO}

A relação que se estabelece entre o público e a obra de arte, é fruto das conexões que o espectador constrói no museu. Nesse sentido, o referente estudo tem como objetivo investigar o uso da parametrização para a concepção de modelos tridimensionais a partir de obras de arte bidimensionais. A metodologia, sob o ponto de vista do problema, utilizou a abordagem qualitativa (investigação) de natureza aplicada (intervenção para fins de verificação), a partir da parametrização de uma obra do acervo da Fundação Iberê Camargo situada em Porto Alegre/RS. A definição dos parâmetros contidos na obra, vislumbra garantir a personalização do artefato, proporcionando uma melhor experiência ao usuário, promovendo a independência, autonomia e a inclusão social de indivíduos nos espaços museais. Como resultados, foram realizadas impressões em alguns parâmetros, para testes.

Palavras-chave: Museologia. Acessibilidade. Tecnologia Assistiva. Parametrização

\footnotetext{
${ }^{1}$ Artigo submetido para avaliação em 19/05/2021 e aprovado em 16/ 06/2021.
} 
Rev. Interd. em Cult. e Soc. (RICS), São Luís, v. 7, n. 1, p. 242 - 258, jan./jun. 2021 ISSN eletrônico: 2447-6498

\begin{abstract}
The relationship established between the public and the work of art is the result of the connections that the spectator builds in the museum. In this sense, this study aims to investigate the use of parameterization for the design of three-dimensional models from two-dimensional works of art. The methodology, from the point of view of the problem, used a qualitative approach (research) of an applied nature (intervention for verification purposes), from the parameterization of a work from the collection of the Iberê Camargo Foundation located in Porto Alegre /RS. The definition of the parameters contained in the work aims to guarantee the personalization of the artifact, providing a better user experience, promoting independence, autonomy and social inclusion of individuals in museum spaces. As a result, prints were performed on some parameters for testing.
\end{abstract}

Keywords: Museology. Accessibility. Assistive Technology. Parameterization.

\title{
1 INTRODUÇÃO
}

No Brasil, os museus têm registrado recorde de público nos últimos anos. As grandes filas mostram que os museus passaram a fazer parte do cotidiano das pessoas, turistas, grupos de jovens, famílias e escolas. Além das consagradas atrações internacionais, que têm participado com maior frequência no Brasil, cujos projetos têm gerado sucesso entre o público local, novos museus, de diferentes tamanhos e temas, estão sendo inaugurados. Se antes os museus estavam restritos à preservação de grandes coleções, hoje eles caminham na direção de explorar a capacidade de reunir pessoas, a fim de permitir novas ou diferentes experiências, compartilhar emoções e provocar discussões relevantes para o desenvolvimento imaterial e cultural da sociedade. Não por acaso, também se multiplicam os espaços de debates, fóruns e pesquisa dentro destas instituições. Neste cenário, vale mencionar a contribuição das mudanças tecnológicas que estão imprimindo novas formas de relacionamento com o público, contribuindo para disseminação de conteúdo, aprendizagem e reflexão para públicos tão diversos.

As reflexões de como as pessoas aprendem no museu e como os museus ensinam, estão associadas aos processos psicoeducativos e cognitivos aplicados no espaço museal, com a preocupação de propor exposições que estimulem a percepção do público (CURY, 2005). Ainda, segundo Cury (2005), procura-se oferecer ao público a oportunidade para um comportamento ativo cognitivo (intelectual e emotivo), interagindo com a exposição. Em síntese, procura-se a interação entre mensagem 
Rev. Interd. em Cult. e Soc. (RICS), São Luís, v. 7, n. 1, p. 242 - 258, jan./jun. 2021

ISSN eletrônico: 2447-6498

expositiva e o visitante, para que a exposição permita uma experiência de apropriação de conhecimento.

Santos (2009) afirma que nos últimos trinta anos foi possível produzir e provocar visíveis transformações no campo da museologia. Considerando que o fazer museológico é o resultado das relações humanas em cada momento histórico, em relação com as demais práticas sociais globais, pode-se afirmar que a museologia é resultado de um mundo em transformação.

Para Martins (2017), a definição tradicional de museu tem sido frequentemente questionada na atualidade frente às novas funções adquiridas por esses espaços, sobretudo no que tange às funções sociais. Uma das asserções da museologia atual é a consciência da heterogeneidade dos públicos que frequentam os museus, ancorada no objetivo de conseguir a maior democratização no contexto atual da sociedade. Esse objetivo parte da noção de que existe uma parte da sociedade que tem usufruído poucas oportunidades na visita aos museus.

Pensando os espaços museais como espaços democráticos que devem ser, vislumbrase que esses locais sejam acessíveis aos mais diferentes públicos. Para Cardoso, Silva e Zardo (2017), os museus devem promover a acessibilidade; o desenvolvimento da autonomia; o diálogo; a oferta de experiências multissensoriais e experiências significativas para todos.

Em diferentes contextos, há entendimentos variados para a expressão acessibilidade que podem levar a propostas diferenciadas de design (MELO; BARANAUSKAS, 2005). O conceito de acessibilidade tem sido associado ao compromisso de melhorar a qualidade de vida de pessoas com deficiência e incapacidades, entretanto, ela também está relacionada com a qualidade de vida de todas as pessoas, como coloca Sassaki et al. (2003 apud VIRVATA, 2011, p.23) ao dizer que para uma sociedade ser acessível é preciso averiguarmos seis quesitos básicos: Acessibilidade Arquitetônica, Acessibilidade Comunicacional, Acessibilidade Metodológica, Acessibilidade Instrumental, Acessibilidade Programática, Acessibilidade Atitudinal e Acessibilidade Tecnológica. Esta última não constitui um outro tipo de acessibilidade, pois o aspecto tecnológico deve permear os demais, à exceção da acessibilidade atitudinal.

Nesse sentido, o objetivo principal deste estudo é investigar como o uso da parametrização na concepção de modelos tridimensionais, a partir de obras de arte bidimensionais, pode desenvolver artefatos para acessibilidade nos museus.

O referencial teórico referente ao objeto de estudo relaciona os conceitos de museologia, tecnologia assistiva e modelagem paramétrica. Neste sentido, foi realizada uma parceria 
Rev. Interd. em Cult. e Soc. (RICS), São Luís, v. 7, n. 1, p. 242 - 258, jan./jun. 2021

ISSN eletrônico: 2447-6498

com a Fundação Iberê Camargo, localizada na cidade de Porto Alegre/RS, para a escolha de uma obra do acervo do artista a partir de critérios definidos previamente.

Como etapa final deste estudo, será apresentado um protótipo tridimensional fabricado através da impressão por filamento fundido.

O referido artigo é uma ampliação do resumo publicado em livro de resumos da IN-

\section{CLUDIT VI ${ }^{2}$}

\section{DESENVOLVIMENTO}

\subsection{As transformações do espaço museal}

Nos últimos trinta anos foi possível observar visíveis transformações no campo da museologia. Conforme Santos (2009), o fazer museológico é o resultado das relações humanas em cada momento histórico. Em relação com as demais práticas sociais globais pode-se afirmar que a museologia é resultado de um mundo em transformação.

As transformações ocorridas na museologia trouxeram novos estudos e estratégias para que a interação entre museu-espectador seja crescente e constante. Hoje, com os novos recursos tecnológicos, um número expressivo de espaços museais tem utilizado dispositivos que potencializam a interação do público com o museu. Conforme Bahia (2015), o museu de arte é uma instituição social, e enquanto tal, é reciclável. Desde seu advento, os museus de arte veem passando por momentos de redefinição de modelos e práticas, vivendo um contínuo processo de transformação. Para Martins (2017), foi a partir de 1990 que uma série de práticas e reflexões ocorridas nos espaços museais ocasionou uma "crise de identidade" do setor museológico. Ainda segundo Martins:

Às tradicionais funções centradas nas coleções dos museus, de conservar, expor e investigar, juntaram-se outras novas, dirigidas aos públicos e às comunidades. Foi reforçada a importância da função comunicativa, da divulgação, do caráter educativo e do sentido lúdico que passaram a assumir a essência e objetivo final do museu. (MARTINS, 2017, p. 84).

\footnotetext{
${ }^{2}$ PEREIRA, Cristiano da Cunha; FAGUNDES, Cristian; SILVA, Tânia Luisa K.; BRUSCATO, Underléa Miotto. Acessibilidade nos museus de arte a partir da parametrização de obras: Fundação Iberê Camargo. Politécnico de Leiria. Livro de Resumos da VI Conferência Internacional para a Inclusão - 2020. Leiria: Centro de Recursos Multimédia, ESECS, Politécnico de Leiria, p. 302-311, 2020.
} 
Rev. Interd. em Cult. e Soc. (RICS), São Luís, v. 7, n. 1, p. 242 - 258, jan./jun. 2021 ISSN eletrônico: 2447-6498

Conforme Sarraf (2015), os espaços culturais têm o desafio de cativar seus visitantes, desenvolvendo o pertencimento cultural através de propostas de mediação multissensoriais, estabelecendo, assim, vínculos sensíveis com seu público.

Para Cury (2005), a comunicação museológica é a denominação genérica que é dada às diversas formas de extroversão do conhecimento em museus, uma vez que há um trabalho de introversão. Já a musealização trata do processo de viabilização da interpretação dos objetos inseridos no espaço museal para que a fruição do espectador seja possível. A comunicação entre o objeto e o público se constitui dentro dos espaços museais a partir da montagem das exposições, a qual pode ser denominada de experimentações museográficas e expográficas. Bahia (2015) atribui aos museus a tarefa de diversificar as formas de comunicação usando novas estratégias de participação e interação da comunidade nos processos de significação do patrimônio e da própria instituição museal.

A museografia engloba todas as ações práticas de um museu: planejamento, arquitetura e acessibilidade, documentação, conservação, exposição e educação (CURY, 2005). Gonçalves (2004) alarga este conceito, afirmando que é por meio da museografia que se cumpre a função primordial da exposição, a de aproximar o objeto mostrado e o visitante. Já na expografia, conforme Cury (2005), são utilizados instrumentos para conceituar e apresentar os objetos, utilizando cores, ambientação, sonorização, iluminação, temperatura e demais dispositivos multissensoriais. Também fazem parte dos elementos expográficos os demais recursos visuais, como textos institucionais, textos curatoriais, fichas técnicas, imagens fotográficas, etc.

A estrutura de apresentação da mostra se torna o canal para a realização do encontro vivo com a obra de arte para a vivência estética, para o diálogo com a arte, sendo, portanto, condição decisiva do seu processo comunicativo. Os artifícios utilizados pela museografia têm como objetivo estabelecer uma experiência cognitiva entre o espectador e o objeto museal exposto.

Quando as exposições são pensadas como meios de comunicação entre público e arte, a conjuntura cultural influi diretamente na compreensão da mensagem. Raras vezes o objeto, em si mesmo, é suficiente para remeter imediatamente os visitantes aos valores trabalhados na exposição. Relações precisam ser estabelecidas pelo público para se chegar a uma compreensão da mostra. Para tanto, o espectador, de antemão, precisa ter - ou adquirir por via da exposição - informações sobre o objeto exibido. Ele precisa, também, captar quais os paradigmas que norteiam o conceito de arte nem determinado momento da história, quais as tendências da época em que se insere a obra; e deve conhecer algo sobre o seu contexto social (GONÇALVES, 2004, p. 34). 
Rev. Interd. em Cult. e Soc. (RICS), São Luís, v. 7, n. 1, p. 242 - 258, jan./jun. 2021

ISSN eletrônico: 2447-6498

Todos os recursos visuais são de extrema importância na construção da narrativa expositiva, transmitindo ideias, acontecimentos e conceitos. Inclui um conjunto de elementos enriquecedores à experiência do público, na medida em que potencializam a interação entre o público e o patrimônio cultural. Serve para consolidar o discurso museológico estruturado na articulação entre os objetos expostos e os demais recursos do museu.

A exposição é a ponta do iceberg que é o processo de musealização, é a parte que visualmente se manifesta para o público e a grande possibilidade de experiência poética por meio do patrimônio cultural. É, ainda, a grande chance dos museus de se apresentarem para a sociedade e afirmarem a sua missão institucional. (CURY, 2005, p. 35).

A nova museologia, segundo Martins (2017), apoia-se na ideia principal de museu como agente social, de contato direto entre o público e as coleções, com um papel específico e flexível que procura atuar e responder às necessidades da sociedade em que se insere.

\subsection{Acessibilidade em Ambientes Culturais}

Um dos princípios da museologia atual é ter a consciência dos diversos públicos que frequentam os museus, no intuito de possibilitar a democratização desses espaços no contexto atual da sociedade. Para Martins (2017), aceitar que o público tradicional não é apenas um, é ter consciência de uma audiência plural em uma só coleção.

No âmbito dos espaços culturais, que aqui representam os ambientes condicionantes do acesso ao patrimônio cultural, durante o século XX ocorreram mudanças substanciais nas teorias e práticas de ação cultural que proporcionam aproximações com as necessidades de tornar os espaços, as estratégias de comunicação, as ferramentas de acesso à informação, a linguagem cultural, as propostas educativas e atendimento acessível para a promoção da inclusão cultural. (SARRAF, 2015. p. 58).

Existe uma deficiência dos espaços museais no Brasil no que se refere à adequação para fins de autonomia e acessibilidade. Segundo Cuty e Cardoso (2012), possibilitar o acesso mínimo e satisfatório ao patrimônio cultural e à informação é a melhor forma de fazer com o museu cumpra o seu principal sentido com a sociedade, legitimando a identidade e a autoidentificação com aquilo que a compõem.

O encontro de públicos tão diversos que frequentam os museus desafiam estas instituições e os profissionais que nela trabalham a corresponder às suas expectativas e, antes de tudo, às suas necessidades. Conforme Cuty e Cardoso (2012), as exigências em ambientes culturais obrigam esses espaços a constantes transformações. Para Martins (2017), aceitar que o público tradicional não é apenas um, é ter 
Rev. Interd. em Cult. e Soc. (RICS), São Luís, v. 7, n. 1, p. 242 - 258, jan./jun. 2021

ISSN eletrônico: 2447-6498

consciência de uma audiência plural em uma só coleção. Ainda segundo Martins (2017, p. 94):

\begin{abstract}
A noção de que os museus têm potencial para atuar como agentes de mudança social e contribuir para melhorar a qualidade de vida das pessoas reflete novas visões e novas funções do museu do século XXI. Na verdade, dentro do setor, há um crescente consenso de que os museus têm a responsabilidade de desempenhar um propósito social, que vai para além da simples função de facilitar o acesso físico, abordando questões e preocupações da agenda social. O modelo social da deficiência tem sido considerado um instrumento conceitual para os museus alterarem as suas práticas tradicionais.
\end{abstract}

Sarraf (2015) afirma que, para tornar os espaços culturais locais acessíveis, é necessário incluir outros públicos que normalmente não são foco das políticas museais, e por essa razão, não se beneficiam dos recursos de comunicação e mediação acessíveis e sensoriais. Entre essas pessoas estão, principalmente, os idosos, as crianças pequenas com suas famílias e os visitantes de primeira viagem. Bins e Oliveira (2005) definem espaço acessível como aquele de fácil compreensão, que permite ao usuário comunicar-se, ir e vir e participar de todas as atividades, sempre com autonomia, segurança e conforto, independente de suas habilidades e restrições.

Muitas das iniciativas beneficiam também a inclusão dos demais públicos, trabalhando outras formas de usufruir os espaços expositivos e suas obras. O Plano Nacional de Cultura (PCN) é uma das mais importantes ferramentas de garantia dos direitos culturais dos brasileiros. Foi aprovado através da Lei n $12.343 / 2010$ e apresenta um conjunto de diretrizes para a cultura brasileira que envolve as esferas municipal, estadual e federal. Em sua diretriz de número 29, o PNC (2010) ${ }^{3}$ visa “[...] garantir que as pessoas com deficiência possam ter acesso aos espaços culturais, seus acervos e atividades" e apresenta uma meta audaciosa quanto às pessoas com deficiência e a cultura: 100\% de bibliotecas públicas, museus, cinemas, teatros, arquivos públicos e centros culturais, atendendo aos requisitos legais de acessibilidade e desenvolvendo ações de promoção da fruição cultural por parte das pessoas com deficiência até 2020.

\title{
2.3 Tecnologia Assistiva
}

Os acessos às tecnologias têm impactado significativamente a forma como as pessoas se relacionam com o mundo. Essas mudanças afetam a realização de atividades do dia-a-dia, as relações humanas, o trabalho e a aprendizagem. Sem dúvida, a habilidade das sociedades

\footnotetext{
${ }^{3}$ Disponível em http://www.planalto.gov.br/ccivil 03/_ato2007-2010/2010/lei/112343.htm.
} 
Rev. Interd. em Cult. e Soc. (RICS), São Luís, v. 7, n. 1, p. 242 - 258, jan./jun. 2021

ISSN eletrônico: 2447-6498

de dominarem a tecnologia e, em especial, aquelas tecnologias, que são estrategicamente decisivas em cada período histórico, traçam o destino a ponto de dizer que, embora não determinem a evolução histórica e a transformação social, a tecnologia incorpora a capacidade de transformação dessas sociedades, bem como os usos que as sociedades decidem dar ao seu potencial tecnológico (CASTELLS, 1999).

Para as pessoas com deficiência, o desenvolvimento de recursos de tecnologia tem possibilitado maneiras de interagir, de se comunicar e de participar em contextos diversos que até bem pouco tempo eram inimagináveis. Historicamente, indivíduos com deficiências físicas e múltiplas severas, sejam congênitas, traumáticas ou induzidas por doença, tiveram autonomia e independência limitadas devido, em grande parte, pela falta de meios alternativos de interagir com o mundo. O conceito nacional de Tecnologia Assistiva foi lançado no Brasil em 20 de abril de 2007 pelo CAT - Comitê de Ajudas Técnicas da Secretaria Especial dos Direitos Humanos da Presidência da República - SEDH. Na legislação brasileira ainda encontraremos o termo Ajudas Técnicas, sendo referido nos Decretos 3.298/1999 e 5.296/2004, que falam do direito das pessoas com deficiência. O artigo $3^{\circ}$ da Lei Brasileira de Inclusão - LIB (2015) define Tecnologia Assistiva como: Produtos, equipamentos, dispositivos, recursos, metodologias, estratégias, práticas e serviços que objetivem promover a funcionalidade, relacionada à atividade e à participação da pessoa com deficiência ou com mobilidade reduzida, visando à sua autonomia, independência, qualidade de vida e inclusão social. (BRASIL, 2015).

O artigo $74^{\circ}$ da LBI (2015) garante às pessoas com deficiência o direito de acesso à tecnologia assistiva. É garantido à pessoa com deficiência acesso a produtos, recursos, estratégias, práticas, processos, métodos e serviços de tecnologia assistiva que maximizem sua autonomia, mobilidade pessoal e qualidade de vida.

O acesso aos produtos desenvolvidos com base em Tecnologia Assistiva ainda não está disponível para todas as pessoas que necessitam de dispositivos específicos para usufruir sua autonomia como cidadão. O alto custo e a produção em pequena escala torna inacessível alguns desses produtos. Conforme Demarchi, Correia, Piffero, Bruscato, Rüthschilling, Aymone e Silva (2017), quando o processo de fabricação é produzido em grande escala a partir da padronização dos processos, dimensões e densidades, as especificidades dos usuários são ignoradas.

Ainda conforme Demarchi et al. (2017), novos métodos digitais de manufatura, como a modelagem paramétrica, surgem como alternativas que têm se mostrado bastante ativas 
Rev. Interd. em Cult. e Soc. (RICS), São Luís, v. 7, n. 1, p. 242 - 258, jan./jun. 2021

ISSN eletrônico: 2447-6498

nos processos de produção de dispositivos com formas complexas, definidas por parâmetros, tendo assim, facilidade em alterá-las, o que torna possível a adaptação dos produtos a diversas especificidades.

\title{
2.4 Modelagem Paramétrica
}

Na matemática, toda a forma paramétrica remete a valores que podem ser atribuídos a uma determinada variável, criando diferentes soluções para um problema por meio de uma única fórmula (CELANI, 2003). Estes valores podem ser chamados de parâmetros, e por meio de regras, possibilitam a criação de relações entre elementos (HENRIQUES, 2013). Estes ambientes paramétricos foram potencializados em virtude do avanço das novas ferramentas computacionais, como se vê abaixo:

\begin{abstract}
A partir do programa Rhinoceros, que opera com recursos NURB, e do Grasshopper, pôde-se avançar na investigação de formas e superfícies topologicamente contínuas de terceiro grau ou superior. Não se trata mais de operar apenas sobre elementos geométricos como linhas e planos, trata-se de operar sobre parâmetros que subjazem à construção geométrica da forma. Assim, a manipulação topológica dos pontos e curvas no espaço, que constituem os elementos geométricos, é que impulsiona as construções de grande complexidade formal e espacial na atualidade. (FLORIO, 2011, p. 45).
\end{abstract}

Segundo Mendes (2018), a parametrização estabelece relações entre os elementos que constituem um desenho, encarando essas relações como processos interativos entre suas propriedades. Estes processos são definidos e planejados pelo designer por meio da criação de algoritmos, o que resulta em uma rápida alternância compositiva, favorecendo a personalização de produtos, conforme a necessidade dos usuários, permitindo soluções específicas. Neste sentido, entende-se a relevância do emprego da modelagem paramétrica em projetos de tecnologia assistiva. Para Ellwanger, Souza, Roque, Bruscato e Silva (2016), os parâmetros, integrados a estes algoritmos, ampliam o campo de possibilidades formais e arquiteturais de um produto, propiciando a manipulação de relações e a constituição de geometrias associativas que não são soluções fixas, sendo assim, todas as partes que compõem um determinado produto correspondem a um todo integrado e se modificam de maneira sistemática e coordenada, estabelecendo conexões, onde poucos elementos que compõem um projeto podem ser modificados, sem perder de suas funcionalidades.

Neste contexto, para a integração total deste processo de projetação, há a necessidade de novos processos de fabricação. Para Mendes (2018), o processo de prototipagem digital pode auxiliar na concepção performativa destes artefatos. Os processos mais utilizados são os subtrativos, aditivos e formativos. Dentre os processos aditivos para a fabricação de objetos 
Rev. Interd. em Cult. e Soc. (RICS), São Luís, v. 7, n. 1, p. 242 - 258, jan./jun. 2021

ISSN eletrônico: 2447-6498

prototipados, o mais difundido atualmente é a Modelagem FDM (FUSED DEPOSITION MODELLING), ou impressão 3D. Neste processo, cada seção transversal é obtida a partir do derretimento e da deposição do filamento de plástico, que ao resfriar se solidifica, criando sólidos tridimensionais (PUPO, 2009). Com isso, diante deste contexto, escolheu-se a impressão 3D para a fabricação do elemento.

\section{PROCEDIMENTOS METODOLÓGICOS}

Os procedimentos metodológicos estão organizados de forma sistemática, buscando investigar o uso de modelos paramétricos para a concepção de um modelo tridimensional da obra Carretéis em Equilíbrio (1959) do artista Iberê Camargo. Assim, os procedimentos dividem-se segundo duas abordagens: qualitativa (investigação) e aplicada (intervenção para fins de verificação).

Os procedimentos adotados foram formulados respectivamente nas seguintes etapas: Etapa 1- escolha de uma obra do artista plástico Iberê Camargo; Etapa 2 - criação do algoritmo com parâmetros oriundos da imagem da obra escolhida; Etapa 3 - impressão tridimensional por filamento fundido do modelo concebido pelo algoritmo.

\subsection{Fundação Iberê Camargo}

A Fundação Iberê Camargo foi criada em 1995, com a missão de preservar, investigar e divulgar a obra de Iberê Camargo, além de aproximar o público deste que é um dos grandes nomes da arte brasileira do século XX, estimulando a reflexão sobre arte, cultura e educação por meio de programas transdisciplinares e do fomento à própria produção artística. A fundação tem como visão ser um centro de excelência dedicado à obra de Iberê Camargo e à reflexão sobre arte moderna e contemporânea, para onde convergem os mais variados públicos e segmentos sociais.

O propósito da fundação é preservar o acervo, promover a pesquisa e a divulgação da obra de Iberê Camargo, estimulando a interação dos públicos da Fundação com a arte, a cultura e a educação a partir de programas transdisciplinares, que dialoguem com as diversas manifestações culturais e os mais variados campos do conhecimento. (Disponível em: http://iberecamargo.org.br - acessado em 17 de maio de 2019).

\subsection{A Obra: Carretéis em Equilíbrio}


Rev. Interd. em Cult. e Soc. (RICS), São Luís, v. 7, n. 1, p. 242 - 258, jan./jun. 2021 ISSN eletrônico: 2447-6498

Dentre as obras que compõem o acervo da Fundação Iberê Camargo estão gravuras, esculturas, pinturas e desenhos. Para a Etapa 1 da pesquisa, foi selecionada uma gravura em metal, confeccionada a partir da técnica de Água-tinta (processo do açúcar), intitulada Carretéis em Equilíbrio, datada de 1959 (Figura 1).

Para a escolha da obra, foram considerados os seguintes critérios:

a) Tamanho: optou-se pela escolha de uma obra com 29,9 por 49,6 cm, para que o processo de impressão fosse viabilizado.

b) Obra em preto e branco: a gravura em preto no suporte de papel bege possibilitou o processo de parametrização das formas.

c) Obra em 2D: para parametrização e confecção de modelo em 3D.

Figura 1: Etapa 1- escolha de uma obra do artista plástico Iberê Camargo

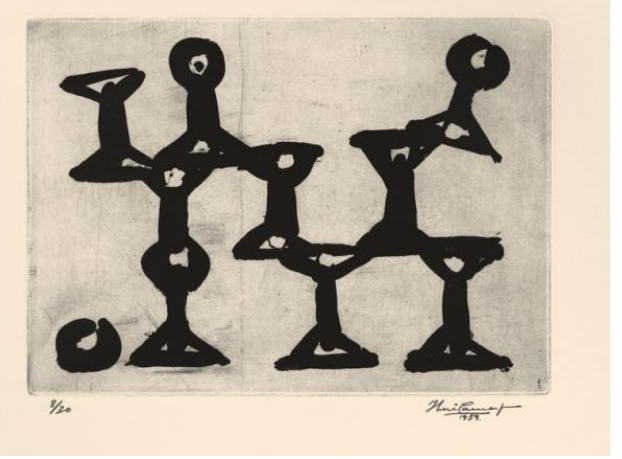

Fonte: Fundação Iberê Camargo, Porto Alegre (2018).

Descrição da Imagem: Sobre um fundo acinzentado, encontra-se um conjunto de nove carretéis de linha de costura empilhados em três fileiras. Os carretéis possuem formas simplificadas e variadas, em tons de preto, contrastando com o fundo bege. Na primeira fileira, três carretéis na posição vertical. À esquerda dessa fileira, uma circunferência que sugere um carretel visto de cima. Na segunda fileira estão empilhados outros três carretéis. Na última fileira, um carretel está empilhado entre dois dos carretéis da segunda fileira, e os demais estão nas extremidades, apoiados apenas por uma pequena parte de sua base, sugerindo um desequilíbrio em relação aos outros carretéis. Ao redor da gravura uma larga borda do papel em bege liso. No canto inferior esquerdo, 8/30; e no canto inferior direito, a assinatura do autor e a data.

\subsection{O Algoritmo}

Como sequência do estudo e após a escolha da obra para a parametrização, realizouse a concepção do algoritmo para a construção do modelo tridimensional - Etapa 2 (Figura 2). Para a etapa, utilizaram-se o software de modelagem, Rhinoceros e o plug-in com o ambiente algorítmico, Grasshopper. Diante isso, realizaram-se três processos: construção bidimensional do modelo virtual por meio da fixação dos limites de largura e altura da peça; parametrização 
Rev. Interd. em Cult. e Soc. (RICS), São Luís, v. 7, n. 1, p. 242 - 258, jan./jun. 2021 ISSN eletrônico: 2447-6498

do fundo-figura, por meio da variação de cores (preto e branco); e criação da tridimensionalidade do modelo, por meio da extrusão de superfícies circulares relacionadas aos parâmetros do contraste de cores, ou seja, nas regiões mais escuras do desenho, apresentaram maiores extrusões.

Figura 2: Etapa 2 - Criação do algoritmo com parâmetros oriundos da imagem da obra escolhida

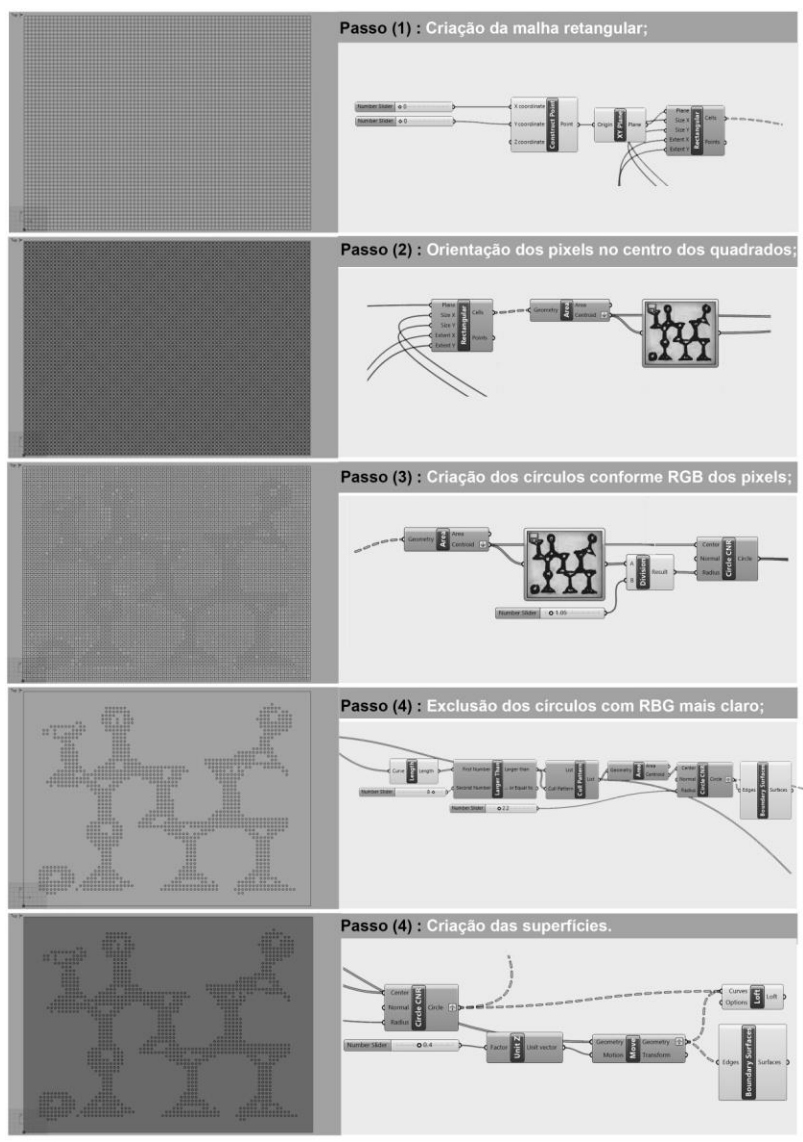

Fonte: Imagem produzida pelos autores.

Descrição da Imagem: A imagem apresenta um quadro com duas colunas e cinco linhas, formando 10 retângulos, cinco menores e cinco maiores. A coluna da esquerda, que possui os cinco retângulos menores, com imagens geradas pelo programa Rhinoceros 3D, apresenta no primeiro retângulo, de cima para baixo, uma malha fina formada por linhas verticais e horizontais em cinza claro, o segundo retângulo apresenta uma malha fina formada por linhas verticais e horizontais em cinza médio, o terceiro retângulo apresenta uma malha fina formada por linhas verticais e horizontais em cinza claro sob a silhueta de nove carretéis empilhados vistos de frente e um visto de cima, todos em um cinza um pouco mais escuro do que o cinza claro do fundo. O quarto retângulo apresenta a mesma silhueta do retângulo anterior, agora preenchida por pequenos pontos acinzentados sobre um fundo cinza claro homogêneo. O último retângulo apresenta a mesma silhueta sobre um fundo cinza médio homogêneo. A coluna da direita, que possui os cinco retângulos maiores, com imagens geradas pelo plugin Grasshopper 3D, apresenta no primeiro retângulo, de cima para baixo, os parâmetros criados para execução do Passo 1 - Criação da malhar retangular, no segundo retângulo apresenta os parâmetros criados para execução do Passo 
Rev. Interd. em Cult. e Soc. (RICS), São Luís, v. 7, n. 1, p. 242 - 258, jan./jun. 2021

ISSN eletrônico: 2447-6498

2 - Orientação dos pixels do centro do quadrados, no terceiro retângulo apresenta os parâmetros criados para a execução do Passo 3 - Criação dos círculos conforme RBG dos pixels, no quarto retângulo identificamos os parâmetros criados para a execução do Passo 4 - Exclusão dos círculos com RGB mais claro e no quinto e último retângulo apresenta os parâmetros criação para a execução do Passo 5 - Criação das superfícies.

\subsection{O Protótipo}

Para melhor elucidação do objetivo proposto, optou-se pela fabricação de um protótipo tridimensional, elaborado com o uso de algoritmo e fabricado através da impressão por filamento fundido. Conforme Werlang, Van der Linden, Bruscato e Bernardes (2018), na manufatura aditiva (ma), o material é adicionado, sintetizado ou enrijecido camada-a-camada na seção transversal, cuja espessura determina a resolução do produto final. Os materiais mais comuns são: polímeros termoplásticos e termofixos, ligas de aço e até metais reativos como o titânio. Também são encontrados de madeira, ceras, papel, argila, concreto, açúcar e chocolate.

Os procedimentos adotados foram formulados respectivamente nas seguintes etapas: Etapa 1- escolha de uma obra do artista plástico Iberê Camargo (Figura 1); Etapa 2 - criação do algoritmo com parâmetros oriundos da imagem da obra escolhida (Figura 2); Etapa 3 impressão tridimensional por filamento fundido do modelo concebido pelo algoritmo (Figura 43).

Após escolha da imagem, a mesma foi utilizada como parâmetro base na concepção do algoritmo. Para isso, criou-se uma malha retangular com 4.524 quadrados, dentre eles 78 distribuídos eixo $\mathrm{X}$ e 58 no eixo $\mathrm{Y}$, os valores foram escolhidos conforme as dimensões da imagem para que a mesma coubesse na malha. A imagem foi inserida no algoritmo através do comando imagem sampler para que cada pixel da figura correspondesse ao centro de cada um dos quadrados.

Logo após a demarcação entre os pixels e os quadrados, inseriu-se círculos no centro de cada relação, totalizando 4.524 objetos. Os raios dos círculos foram definidos através da divisão entre a escala do RGB (intervalo de 255 para cores com tons claros e 0 para tons escuros) e um fator divisório aleatório (onde a dimensão do círculo não ultrapassasse as bordas dos quadrados). Logo após, foram excluídos os círculos com a tonalidade mais clara, tornando nítido o desenho da figura.

Para a criação das superfícies, copiou-se todos os círculos no eixo $\mathrm{Z}$ e alterou-se a dimensão dos mesmos para obter uma suavização na extrusão. Por fim, através do comando 
Rev. Interd. em Cult. e Soc. (RICS), São Luís, v. 7, n. 1, p. 242 - 258, jan./jun. 2021

ISSN eletrônico: 2447-6498

loft uniu-se as superfícies dos círculos bases e dos círculos movidos no eixo Z, criando assim um modelo tridimensional.

Foram geradas 1.160 superfícies, criando assim, uma gravura com baixo relevo. $\mathrm{Ob}-$ teve-se aproximadamente $4 \mathrm{mb}$ de tamanho total do modelo que logo após foi testado na impressão por filamento fundindo.

\section{RESULTADOS E DISCUSSÕES}

A impressão do modelo foi assistida através da impressora Cliever, no qual utilizou-se o material PLA (plástico de poliácido láctico) para a concepção da peça. (Figura 3).

Figura 3: Etapa 3 - impressão tridimensional por filamento fundido do modelo concebido

$$
\text { pelo algoritmo }
$$
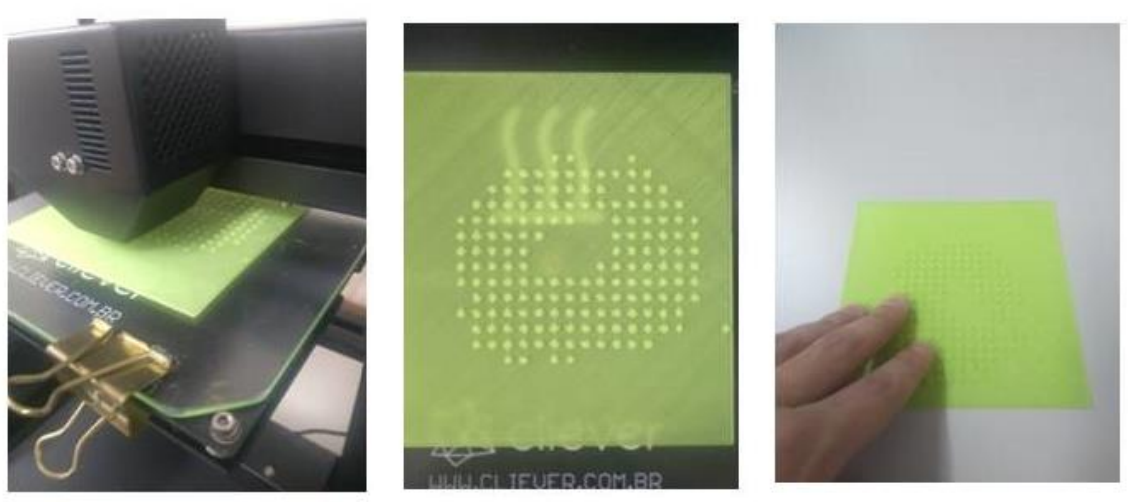

Fonte: Imagem produzida pelos autores.

Descrição da Imagem: A figura é composta por três fotografias que demostram as etapas de impressão do protótipo tridimensional por filamento fundido na impressora Cliever. Da esquerda para a direita, a primeira fotografia apresenta a impressora Cliever realizando o processo de impressão do protótipo 3D. A segunda fotografia apresenta o protótipo impresso, visto de cima, representando um fragmento da obra Carretéis em Equilíbrio. Este fragmento representa um carretel visto de cima, e tem sua forma representada por diversos pontos em relevo de aproximadamente dois milímetros de altura. A terceira fotografia apresenta o protótipo impresso sob a mão do autor, que toca levemente os pontos em relevo que compõem a imagem, analisando a volumetria da peça.

Após a impressão tridimensional do modelo, observou-se que o fragmento é visualmente indentificável com parte da obra parametrizada. Também é perceptível, ao toque, que o modelo impresso é compatível à imagem utilizada como referência. O contraste entre o preto e branco da obra bidimensional é transposto para o modelo tridimensional impresso, mantendo a mesma volumetria (altura dos pontos impres- 
Rev. Interd. em Cult. e Soc. (RICS), São Luís, v. 7, n. 1, p. 242 - 258, jan./jun. 2021

ISSN eletrônico: 2447-6498

sos) em toda a sua extensão. Sendo assim, a percepção visual de contraste da obra (preto e branco), é também perceptível no tato do modelo tridimensional, onde só existem duas alturas, a da impressão e a do material que foi utilizado como base.

\section{CONSIDERAÇÕES FINAIS}

Partindo dessa pesquisa, é possível observarmos que o uso do algoritmo para a concepção de modelos auxilia desde o processo criativo à etapa final de fabricação.

Para esse estudo, utilizou-se ferramentas para a criação física de um protótipo, onde os parâmetros iniciais do algoritmo são originados através de uma imagem comum, em que a mesma fornece informações na escala RGB (tons claros e escuros) para que o algoritmo manipule e facilite na criação tridimensional do protótipo.

É importante ressaltar que nesta pesquisa não foram utilizados critérios técnicos para leituras táteis, visto que a intenção do estudo em primeiro momento é a elaboração de modelos tridimensionais (oriundos de imagens bidimensionais) através de algoritmos.

A identificação, a partir da visão, dos elementos formais e cromáticos, encontrados na gravura de Iberê Camargo, a partir do protótipo, agora também são reconhecidos pelo tato, tornando a prototipagem digital mais uma ferramenta para elaboração de dispositivos de acessibilidade. O protótipo impresso por filamento fundido, resultante dessa pesquisa, auxiliará futuros estudos desenvolvidos com base em Tecnologia Assistiva, acerca da percepção de usabilidade das pessoas com deficiência nos museus.

Sendo os museus, espaços dinâmicos e que necessitam de transformações constantes, o referido estudo contribuirá para a implementação de novas estratégias museográficas que auxiliem na ressignificação desses seus espaços, proporcionando aos mais diversos públicos, autonomia na análise e fruição de obras de arte, possibilitando o mínimo e satisfatório acesso à informação, legitimando assim o papel social do museu.

\section{REFERÊNCIAS}

BAHIA, Ana Beatriz. Museu virtual (e plural) de arte. Visualidades (UFG), v. 13, p. 146163, jan-jun 2015.

BINS ELY, Vera H. M.; OLIVEIRA, Aíla S. D. A. de. Acessibilidade em Edifício de Uso Público: Contribuição de Projeto de Extensão na Elaboração de Dissertação. In: Projetar 2005-II Seminário sobre Ensino e pesquisa em projeto de Arquitetura, Rio de Janeiro, 2005. 
Rev. Interd. em Cult. e Soc. (RICS), São Luís, v. 7, n. 1, p. 242 - 258, jan./jun. 2021

ISSN eletrônico: 2447-6498

BRASIL. CENSO 2010 - Pessoas com Deficiência [Cartilha]. Brasília: Secretaria de Direitos Humanos da Presidência da República (SDH/PR) / Secretaria Nacional de Promoção dos Direitos da Pessoa com Deficiência (SNPD) / Coordenação-Geral do Sistema de Informações sobre a Pessoa com Deficiência.

BRASIL. Presidência da República. Secretaria Geral. Suchefia para Assuntos Jurídicos. Congresso Nacional. LEI No 13.146, DE 6 DE JULHO DE 2015. Institui a Lei Brasileira de Inclusão da Pessoa com Deficiência (Estatuto da Pessoa com Deficiência). Disponível em: <http://www.planalto.gov.br/ccivil_03/_ato2015-2018/2015/lei/113146.htm>

CARDOSO, Eduardo; SILVA, Tânia Luisa K.; ZARDO, Kemi O. Design para experiência multissensorial em museus. Rev. FAEEBA - Ed. e Contemp., Salvador, v. 26, n. 50, p. 135158, set./dez. 2017.

CASTELLS, Manuel. A Sociedade em Rede. 6. ed. São Paulo, Paz e Terra, 1999.

CELANI, Gabriela. Cad criativo. Rio de Janeiro, Campus, 2003.

CURY, Maríla Xavier. Exposição: concepção, montagem e avaliação. São Paulo, Annablume, 2005.

CUTY, Jennifer; CARDOSO, Eduardo. Acessibilidade em Ambientes Culturais. Porto Alegre, Marcavisual, 2005.

DEMARCHI, Gustavo S.; CORREIA, Ricardo; PIFFERO, Victória; BRUSCATO, Underléa M.; RÜTHSCHILLING, Evelise; AYMONE, José Luis F.; SILVA, Tânia Luisa K. O Desenho Paramétrico como facilitador na personalização de órteses para Tecnologia Assistiva. SIGraDi 2017, XXI Congreso de la Sociedad Ibero-americana de Gráfica Digital, Concepción, Chile, 2017. p. 22-24.

ELLWANGER, Cristiane; SOUZA, Vinicius N. R. S; ROQUE, Alexandre dos S.; BRUSCATO, Underléa M.; SILVA, Régio P. Experiência e parametrização no processo de projeto de aplicações digitais interativas. Gestão e Tecnologia de Projetos, São Carlos, v. 11, n. 1, p. 720, jan.-jun., 2016.

FLORIO, Wilson. Modelagem paramétrica, criatividade e projeto: duas experiências com estudantes de arquitetura. Gestão e Tecnologia de Projetos, São Carlos, v. 6, n. 2, p. 43-66, Dezembro, 2011.

GONÇALVES, Lisbeth R. Entre Cenografias: O Museu e a Exposição de Arte no Século XX. São Paulo, Universidade de São Paulo, Fapesp, 2004.

HENRIQUES, Gonçalo Lencastre. T. de C. Tetra Script: sistema de aberturas responsivo para controlar a luz, de acordo com fatores externos e internos. 2013. $448 \mathrm{f}$. Tese (Doutorado em Arquitetura) - Faculdade de Arquitetura, Universidade Técnica de Lisboa, Lisboa, Portugal, 2013.

MARTINS, Patrícia Roque. Museus (In)capacitantes: Deficiência, Acessibilidade e Inclusão em Museus de Arte. Casal de Cambra, Caleidoscópio, 2017. 
Rev. Interd. em Cult. e Soc. (RICS), São Luís, v. 7, n. 1, p. 242 - 258, jan./jun. 2021 ISSN eletrônico: 2447-6498

MELO, Amanda M.; BARANAUSKAS, Maria Cecília. Design para a Inclusão: desafios e proposta. In: Simpósio sobre Fatores Humanos em Sistema Computacionais, Natal, RN, 2005. p. 11-20.

MENDES, Letícia Teixeira. Gramática da forma: aplicações em habitação social. In: CELANI, M. G. C.; SEDREZ, M. (Org.) Arquitetura contemporânea e automação: prática e reflexão. São Paulo, Pro Books, p. 41-54, 2018.

PEREIRA, Cristiano da Cunha; FAGUNDES, Cristian; SILVA, Tânia Luisa K.; BRUSCATO, Underléa Miotto. Acessibilidade nos museus de arte a partir da parametrização de obras: Fundação Iberê Camargo. Politécnico de Leiria. Livro de Resumos da VI Conferência Internacional para a Inclusão - 2020. Leiria, Centro de Recursos Multimédia, ESECS, Politécnico de Leiria, p. 302-311, 2020.

PUPO, Regiane Trevisan. A inserção da prototipagem e fabricação digitais no processo de projeto: um novo desafio para o ensino da arquitetura / Regiane Trevisan Pupo. Campinas, SP, [s.n.], 2009.

SANTOS, Maria Célia Teixeira. M. Processo Museológico: Critérios de Exclusão. Cadernos de Sociomuseologia, [S.I.], v. 18, n.18, junho, 2009.

SARRAF, Viviane P. Acessibilidade em espaços culturais: mediação e comunicação sensorial. São Paulo, EDUC, FAPESP, 2015.

LINDEN, Júlio Carlos de Souza van der; BRUSCATO, Underléa Miotto; BERNARDES, Mauricio Moreira e Silva (Orgs.). Design em pesquisa. Vol 2. Porto Alegre, Marcavisual, 2018. p. $395-411$ 